\title{
Near-infrared spectroscopy to monitor cerebral oxygen saturation in single-ventricle physiology
}

\author{
Marco Ricci, MD, a Pierluca Lombardi, MD, ${ }^{a}$ Steven Schultz, MD, ${ }^{\mathrm{b}}$ Alvaro Galindo, MD, ${ }^{\mathrm{c}}$ Ernesto Coscarella, MD, \\ Amelia Vasquez, ${ }^{\mathrm{c}}$ and Eliot Rosenkranz, $\mathrm{MD}^{\mathrm{a}}$
}

From the Division of Cardiothoracic Surgery, ${ }^{\mathrm{a}}$ Pediatric Cardiology, ${ }^{\mathrm{b}}$ Pediatric Critical Care, ${ }^{\mathrm{c}}$ and the Department of Neurological Surgery, ${ }^{\mathrm{d}}$ University of Miami Miller School of Medicine, Miami, Fla.

Supported by the DeWitt Daughtry Family Department of Surgery of the University of Miami Miller School of Medicine.

Read at the Thirty-first Annual Meeting of The Western Thoracic Surgical Association, Victoria, BC, Canada, June 22-25, 2005.

Received for publication May 10, 2005; revisions received June 20, 2005; accepted for publication July 12, 2005.

Address for reprints: Marco Ricci, MD, Division of Cardiothoracic Surgery, University of Miami Miller School of Medicine, Holtz Center 3072 (R-114), 1611 NW 12th Ave, Miami, FL, 33136 (E-mail: mricci@ med.miami.edu).

J Thorac Cardiovasc Surg 2006;131:395-402

$0022-5223 / \$ 32.00$

Copyright () 2006 by The American Association for Thoracic Surgery

doi:10.1016/j.jtcvs.2005.07.039
Objectives: Near-infrared spectroscopy monitors cerebral oxygen saturation. This parameter parallels jugular venous oxygen saturation and reflects the balance between cerebral oxygen supply and demand. Experience with near-infrared spectroscopy in univentricular physiology is limited. This study explores the relationship between cerebral oxygen saturation, jugular venous oxygen saturation, and other variables of cerebral perfusion in a model of univentricular physiology.

Methods: Univentricular physiology was created in newborn piglets by means of an aortopulmonary shunt, echocardiography-guided atrial septostomy, tricuspid valve avulsion, and pulmonary artery occlusion. Intra-aortic balloon inflation was used to increase afterload. Cerebral oxygen saturation monitoring (INVOS 5100; Somanetics Corp, Troy, Mich), physiologic recordings, and stable-isotope microsphere determination of cerebral blood flow were performed at baseline and after conversion to univentricular physiology (30 minutes, 120 minutes, and during afterload augmentation).

Results: Univentricular physiology resulted in lower cerebral oxygen saturation, arterial oxygen content, jugular venous oxygen saturation, and cerebral oxygen delivery. Afterload augmentation increased cerebral oxygen saturation, arterial oxygen content, and jugular venous oxygen saturation, whereas cerebral oxygen delivery was unaffected because of lower cerebral blood flow. Cerebral oxygen saturation predicted jugular venous oxygen saturation, arterial oxygen saturation, and arterial oxygen content. No association was found with cerebral oxygen delivery, which decreased in parallel with cerebral oxygen saturation when the singleventricle physiology model was established but failed to increase during afterload augmentation.

Conclusions: This study shows that in univentricular physiology cerebral oxygen saturation correlates well with jugular venous oxygen saturation, arterial oxygen saturation, and arterial oxygen content. However, our findings suggest that in singe-ventricle physiology changes in cerebral oxygen saturation need to be interpreted in the context of changes in arterial oxygenation.

$\mathrm{T}$ Transcranial near-infrared spectroscopy (NIRS) is a novel technology used clinically to monitor regional cerebral $\mathrm{O}_{2}$ saturation $\left(\mathrm{rSO}_{2}\right) .{ }^{1}$ It allows the noninvasive detection of changes in the ratio of oxyhemoglobin to deoxyhemoglobin $\left(\mathrm{rSO}_{2}\right.$ index) in the frontal cortex, thus providing indirect information on the adequacy of cerebral oxygenation. ${ }^{2}$

Previous experience with NIRS in clinical practice has focused primarily on the detection of cerebral hypoxia in the context of normoxia and biventricular physiology. ${ }^{3,4}$ In this setting $\mathrm{rSO}_{2}$ has been shown to parallel jugular venous $\mathrm{O}_{2}$ saturation $\left(\mathrm{jvSO}_{2}\right.$ ) consistently. ${ }^{5} \mathrm{RSO}_{2}$ monitoring has been found to be useful in a variety of clinical settings, especially cardiac and vascular surgery, as a surrogate indicator of 


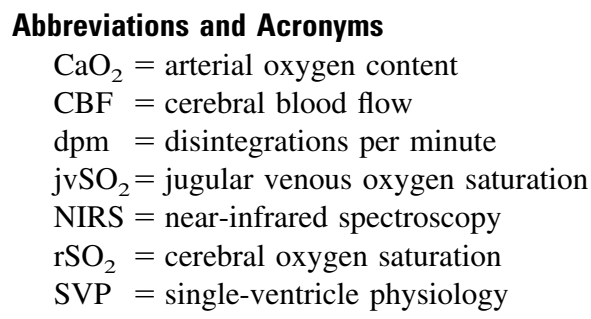

the adequacy of cerebral perfusion. ${ }^{6,7}$ Because NIRS is used as a trend monitor, a decrease in $\mathrm{rSO}_{2}$ can reflect a shift in the balance between cerebral oxygen supply and demand and therefore suggests cerebral hypoxia.

Few studies on the use of NIRS in children with congenital heart disease have been reported ${ }^{8-10}$ and the experience with this technology in cyanotic children with singleventricle physiology (SVP) is limited. ${ }^{11}$ In contrast to biventricular physiology, rapid changes in systemic and pulmonary vascular resistance can produce changes in cerebral perfusion in SVP, as well as significant fluctuations in pulmonary blood flow and therefore arterial oxygenation. Previous reports have indicated that NIRS is heavily influenced by markers of arterial oxygenation, such as arterial $\mathrm{O}_{2}$ content $\left(\mathrm{CaO}_{2}\right)$ and arterial $\mathrm{O}_{2}$ saturation. ${ }^{12}$ We hypothesized that changes in arterial oxygenation occurring simultaneously with changes in cerebral blood flow (CBF) could influence the ability of transcranial NIRS to predict changes in cerebral oxygenation. In our study we investigated the relationship between $\mathrm{rSO}_{2}$, as measured with a commercially available NIRS device, and $\mathrm{jvSO}_{2}$ in an animal model of hypoxemia and SVP. We also explored the association between $\mathrm{rSO}_{2}$, cerebral $\mathrm{O}_{2}$ delivery, and other physiologic variables of cerebral oxygenation in an environment in which simultaneous changes in $\mathrm{CaO}_{2}$ and $\mathrm{CBF}$ were induced by afterload augmentation.

\section{Methods}

\section{Animals}

Eight Yorkshire newborn piglets $(3.7 \pm 0.5 \mathrm{~kg})$ were used. The study was approved by the Animal Care and Use Committee of the University of Miami Miller School of Medicine and carried out in compliance with the 1996 National Research Council guidelines on the Care and Use of Laboratory Animals.

\section{Surgical Preparation}

Piglets were anesthetized with intramuscular ketamine $(40 \mathrm{mg} / \mathrm{kg})$ and xylaxine $(4 \mathrm{mg} / \mathrm{kg})$, intubated through a tracheostomy, and started on volume-control ventilation (tidal volume, $25-30 \mathrm{~mL} / \mathrm{kg}$; rate, 25 breaths/min; inspired $\mathrm{O}_{2}$ fraction, 0.25). Anesthesia was maintained with continuous infusion of fentanyl (50 $\left.\mu \mathrm{g} \cdot \mathrm{kg}^{-1} \cdot \mathrm{h}^{-1}\right)$, pancuronium $\left(0.4 \mu \mathrm{g} \cdot \mathrm{kg}^{-1} \cdot \mathrm{h}^{-1}\right)$, and midazolam $\left(0.2 \mathrm{mg} \cdot \mathrm{kg}^{-1} \cdot \mathrm{h}^{-1}\right)$. A catheter was inserted in the femoral artery for pressure monitoring and blood sampling. A 6F intro- ducer sheath to be used for intra-aortic balloon dilation (afterload augmentation) was inserted in the opposite femoral artery. A 7F introducer sheath was placed in the femoral vein for fluid administration and subsequent insertion of an atrial septostomy catheter. A catheter was inserted in the left internal jugular vein for venous blood sampling. Electrocardiography, rectal temperature, and $\mathrm{rSO}_{2}$ were monitored.

The single-ventricle model resembled that described by others. ${ }^{13,14}$ Through a median sternotomy, catheters were placed in the right and left atrium. Heparin was administered (150 U/kg), and a $3.5-\mathrm{mm}$ polytetrafluoroethylene* shunt was interposed between the aorta (proximal to the take-off of the innominate artery) and the pulmonary artery. While the shunt was clamped, a 2-mL balloon septostomy catheter (Medtronic Vascular, Danvers, Mass) was advanced from the right femoral vein into the right atrium. Epicardial 2-dimensional echocardiography was used to direct the catheter across the atrial septum and perform a pull-back septostomy. The same catheter was then advanced into the right ventricle. The tricuspid valve was made incompetent by repeatedly withdrawing the inflated balloon across the valve. Finally, the shunt was opened, and the main pulmonary artery was occluded. This allowed the left ventricle to support both the systemic and pulmonary circulations, reproducing a physiology similar to that of pulmonary atresia with intact ventricular septum.

\section{Experimental Protocol}

Eight piglets were included in the study group. Animals were ventilated at a constant fraction of inspired oxygen of $25 \%$, adjusting the respiratory rate to maintain a $\mathrm{PCO}_{2}$ of between 35 and $45 \mathrm{~mm} \mathrm{Hg}$. Rectal temperature was kept at $35.5^{\circ} \mathrm{C}$ to $36.5^{\circ} \mathrm{C}$. On the basis of experience from previous pilot experiments, normal saline $\left(4 \mathrm{~mL} \cdot \mathrm{kg}^{-1} \cdot \mathrm{h}^{-1}\right)$, dopamine $\left(5-10 \mu \mathrm{g} \cdot \mathrm{kg}^{-1} \cdot \mathrm{min}^{-1}\right)$, and epinephrine $\left(0.05-0.1 \mu \mathrm{g} \cdot \mathrm{kg}^{-1} \cdot \mathrm{min}^{-1}\right)$ were administered in all animals throughout the entire experiment to maintain cardiovascular stability and avoid hemodynamic perturbations. Calcium gluconate and sodium bicarbonate were given as needed. Fresh whole blood was obtained from an adult pig and infused to maintain a hemoglobin concentration as close to baseline as possible.

Data collection was carried out at baseline and after conversion to SVP (30 minutes, 120 minutes, and during afterload augmentation). Measurements during afterload augmentation were obtained 15 minutes after inflating a balloon in the distal descending thoracic aorta. Data collected included hemodynamic parameters, blood sampling (arterial, central venous, and cerebral venous, hemoglobin, and lactate), determination of total cardiac output with an electromagnetic flowmeter, determination of CBF with stable-isotope microsphere injections, and transcranial measurement of $\mathrm{rSO}_{2}$ by using NIRS. At completion, piglets were killed with $\mathrm{KCl}$ and fentanyl. An autopsy was performed to confirm the correct positioning of all indwelling catheters and the adequacy of the atrial septostomy and that of the aortopulmonary shunt anastomoses. The brain was removed and weighed for blood flow determinations.

*Gore-Tex shunt, registered trademark of W.L. Gore \& Associates, Inc, Newark, Del. 


\section{Determination of CBF}

Stable-isotope microspheres (15 $\pm 5 \mu \mathrm{m}$; BioPhysics Assay Laboratory, Inc, Worcester, Mass) were used as described by others. ${ }^{15}$ Microspheres labeled with nonradioactive isotopes were administered over 3 seconds through the left atrial catheter, and reference samples were collected over 90 seconds from the femoral artery $(2$ $\mathrm{mL} / \mathrm{min}$ ). A total of $1 \times 10^{6}$ microspheres was injected in the biventricular state, whereas $2.5 \times 10^{6}$ were injected in SVP. Experience with microspheres in a univentricular model is lacking in the literature. On the basis of our previous experiments, we demonstrated that $2.5 \times 10^{6}$ microspheres in the univentricular state compensated for run-off through the pulmonary circulation and ensured adequate microsphere concentration in the brain. At the end of the experiment, tissue samples were obtained from different brain regions (cortex, white matter, thalamus, hippocampus, brainstem, and cerebellum), weighed fresh, and dried in a warming oven at $60^{\circ} \mathrm{C}$ for 48 hours. Dried samples were sent for analysis and processed by using neutron activation. ${ }^{15}$ This technique entails exposure of the isotope to a neutron beam, which results in an activated radioactive nucleus. Activated labels are then allowed to decay for 48 hours, during which gamma rays are emitted and measured. The signal is proportional to the concentration of the isotope in the sample. Results of the assay for each label are reported in disintegrations per minute (dpm). CBF is expressed in milliliters per minute per 100 grams and calculated by normalizing the concentration of microspheres in the tissue sample (dpm per gram) to the concentration in the reference sample (dpm per minute per milliliter). Total CBF was calculated by averaging all measurements obtained from both hemispheres.

\section{Determination of $\mathrm{rSO}_{2}$}

A commercially available device (INVOS 5100 Cerebral Oxymeter; Somanetics Corp, Troy, Mich) was used to measure the tissue oxygen saturation index $\left(\mathrm{rSO}_{2}\right.$ index) in the frontal cerebral cortex. $^{5,8}$ This technology entails the use of near-infrared light (730-nm and 810-nm wavelength) to measure the absorption spectra of oxyhemoglobin and deoxyhemoglobin. After shaving the scalp, a 30-mm patch containing the NIRS-emitting source and sensor was placed on the forehead and connected to the infrared spectrophotometer unit. The NIRS probe measures the $\mathrm{rSO}_{2}$ index in a banana-shaped volume of tissue of $1.5 \mathrm{~cm}^{3}$ in depth, subtracting superficial light-scattering signals that originate from extracranial tissues. The device monitor displays data continuously, although for the statistical analysis, we used NIRS data collected at steady state at selected data points simultaneously with arterial and jugular venous blood gases.

\section{Physiologic Measurements and Calculations}

Total cardiac output (excluding coronary blood flow) was determined by using an electromagnetic flowmeter (Transonic Systems, Inc, Ithaca, NY) placed on the ascending aorta. After conversion to SVP, pulmonary blood flow was determined by placing the flowmeter on the pulmonary artery distal to the aortopulmonary shunt, as described by others. ${ }^{13,14}$

Total left ventricular outflow indexed by body weight was calculated as left ventricular output (in milliliters) per minute divided by body weight (in kilograms). The pulmonary/systemic blood flow ratio was calculated as pulmonary blood flow (in milliliters per minute) divided by systemic blood flow (excluding coronary flow, in milliliters per minute). $\mathrm{CaO}_{2}$ was calculated as follows: Hemoglobin $\left.\times 1.36 \times \mathrm{SaO}_{2}\right)+\left(0.0031 \times \mathrm{PaO}_{2}\right)$. Cerebral $\mathrm{O}_{2}$ delivery (in milliliter of $\mathrm{O}_{2}$ per milliliter) was calculated as the product of $\mathrm{CBF}$ (in milliliters per minute per $100 \mathrm{~g}$ ) and $\mathrm{CaO}_{2}$ (in milliliters of $\mathrm{O}_{2}$ per $100 \mathrm{~mL}$ ). The arteriovenous $\mathrm{O}_{2}$ saturation difference was calculated as the difference between arterial $\mathrm{O}_{2}$ saturation and $\mathrm{jvSO}_{2}$.

\section{Statistical Analysis}

All physiologic data are expressed as means \pm SEM. Normal distribution of variables was assessed with the Kolmogorov-Smirnov normality test. Relations between $\mathrm{rSO}_{2}$ and other variables were determined by means of least-squares regression analysis and calculation of Pearson correlation coefficients. One-way repeatedmeasures analysis of variance was used to compare physiologic data obtained at different data points during the experiment (baseline, 30 minutes, 120 minutes, and during afterload augmentation).

\section{Results}

Relevant physiologic data are summarized in Table 1. Temperature and hemoglobin concentration remained unchanged throughout the experiment. Dopamine administration was unchanged during the experiment (from $7.1 \pm 0.8$ to $7.8 \pm 0.8,6.5 \pm 0.8$, and $6.0 \pm 0.8 \mu \mathrm{g} \cdot \mathrm{kg}^{-1} \cdot \mathrm{min}^{-1}$ at baseline, 30 minutes, 120 minutes, and afterload augmentation, respectively), as was epinephrine administration (from $0.07 \pm 0.01$ to $0.07 \pm 0.01,0.06 \pm 0.01$, and $0.06 \pm$ $0.01 \mu \mathrm{g} \cdot \mathrm{kg}^{-1} \cdot \mathrm{min}^{-1}$ at various experimental data points). Total left ventricular output increased significantly after conversion to SVP. The pulmonary/systemic blood flow ratio trended higher from 30 minutes to 120 minutes and increased significantly during afterload increase. Creation of SVP resulted in a significant decrease in diastolic arterial pressure, $\mathrm{rSO}_{2}$, arterial $\mathrm{O}_{2}$ saturation, $\mathrm{CaO}_{2}$, and $\mathrm{jvSO}_{2}(P$ $<.05$ ) and in a trend toward lower cerebral $\mathrm{O}_{2}$ delivery. Afterload augmentation caused an increase in $\mathrm{rSO}_{2}$, arterial $\mathrm{O}_{2}$ saturation, $\mathrm{CaO}_{2}$, and $\mathrm{jvSO}_{2}(P<.05)$, whereas cerebral $\mathrm{O}_{2}$ delivery remained unaffected as a consequence of $\mathrm{CBF}$ trending lower (Table 1).

Table 2 shows the Pearson correlation coefficient and coefficient of determination $\left(R\right.$ and $R^{2}$ ) for each variable tested against the $\mathrm{rSO}_{2}$ index. A significant positive correlation was noted between $\mathrm{rSO}_{2}$ and arterial $\mathrm{O}_{2}$ saturation, $\mathrm{jvSO}_{2}, \mathrm{CaO}_{2}$, and jugular venous oxygen content $(P<$ .0001). A weak correlation was noted between $\mathrm{rSO}_{2}$ and CBF $(R=-0.39, P=.05)$ and between $\mathrm{rSO}_{2}$ and cerebral $\mathrm{O}_{2}$ delivery $(R=0.29, P=.1)$, whereas the low coefficient of determination $\left(R^{2}\right)$ suggested a lack of predictive value of $\mathrm{rSO}_{2}$ for both variables.

Figures 1 through 5 illustrate the statistical relationship between $\mathrm{rSO}_{2}$ and other physiologic variables. Linear relations were observed between $\mathrm{rSO}_{2}$ and arterial $\mathrm{O}_{2}$ saturation (Figure 1), $\mathrm{jvSO}_{2}$ (Figure 2), and $\mathrm{CaO}_{2}$ (Figure 3). Con- 
Table 1. Physiologic data at various experimental data points

\begin{tabular}{|c|c|c|c|c|}
\hline Variable & Baseline & $30 \mathrm{~min}$ & $120 \mathrm{~min}$ & Afterload \\
\hline $\mathrm{rSO}_{2}$ index & $45 \pm 2$ & $19 \pm 2^{*}$ & $25 \pm 2^{*}$ & $44 \pm 2 \dagger \ddagger$ \\
\hline Temperature $\left({ }^{\circ} \mathrm{C}\right)$ & $36.1 \pm 0.2$ & $35.1 \pm 0.2$ & $36 \pm 0.3$ & $35.9 \pm 0.3$ \\
\hline Heart rate (beats/min) & $160 \pm 15$ & $181 \pm 7$ & $195 \pm 5$ & $199 \pm 5^{*}$ \\
\hline Systolic arterial pressure $(\mathrm{mm} \mathrm{Hg})$ & $113 \pm 4$ & $114 \pm 5$ & $119 \pm 5$ & $157 \pm 8^{*}$ \\
\hline Diastolic arterial pressure $(\mathrm{mm} \mathrm{Hg})$ & $67 \pm 4$ & $47 \pm 3^{*}$ & $55 \pm 6$ & $79 \pm 3 † \ddagger$ \\
\hline Mean arterial pressure $(\mathrm{mm} \mathrm{Hg})$ & $84 \pm 4$ & $69 \pm 4$ & $79 \pm 6$ & $108 \pm 4 \dagger \ddagger$ \\
\hline Total LV outflow indexed $\left(\mathrm{mL} \cdot \mathrm{kg}^{-1} \cdot \min ^{-1}\right)$ & $129 \pm 13$ & $202 \pm 19^{*}$ & $226 \pm 15^{*}$ & $233 \pm 12^{*}$ \\
\hline Qp/Qs & NA & $0.97 \pm 0.1$ & $1.44 \pm 0.1$ & $1.73 \pm 0.1 \dagger$ \\
\hline Arterial $\mathrm{pH}$ & $7.40 \pm 0.03$ & $7.25 \pm 0.02^{*}$ & $7.28 \pm 0.04$ & $7.31 \pm 0.03$ \\
\hline $\mathrm{pCO}_{2}(\mathrm{~mm} \mathrm{Hg})$ & $38 \pm 4$ & $47 \pm 3$ & $47 \pm 4$ & $33 \pm 4 \dagger \ddagger$ \\
\hline Arterial $\mathrm{O}_{2}$ saturation $(\%)$ & $98 \pm 1$ & $67 \pm 4^{*}$ & $74 \pm 2^{*}$ & $88 \pm 2 \dagger \ddagger$ \\
\hline $\mathrm{Hb}(\mathrm{g} / \mathrm{dL})$ & $9.3 \pm 0.5$ & $9.4 \pm 0.3$ & $10 \pm 0.3$ & $10.1 \pm 0.2$ \\
\hline Arterial $\mathrm{O}_{2}$ content $\left(\mathrm{mL} \mathrm{O}_{2} / 100 \mathrm{~mL}\right)$ & $12.8 \pm 0.7$ & $8.5 \pm 0.3^{*}$ & $11 \pm 0.5$ & $12.4 \pm 0.8 \dagger$ \\
\hline Jugular venous $\mathrm{O}_{2}$ saturation (\%) & $59 \pm 4$ & $33 \pm 2^{*}$ & $43 \pm 2$ & $58 \pm 5 \dagger$ \\
\hline Cerebral blood flow $(\mathrm{mL} / \mathrm{min}$ per $100 \mathrm{~g})$ & $63 \pm 5$ & $77 \pm 8$ & $61 \pm 12$ & $46 \pm 5$ \\
\hline Cerebral $\mathrm{O}_{2}$ delivery $\left(\mathrm{mL} \mathrm{O}_{2} / \mathrm{min}\right.$ per $\left.100 \mathrm{~g}\right)$ & $8.5 \pm 1$ & $6.4 \pm 0.6$ & $6.3 \pm 1$ & $6.8 \pm 0.8$ \\
\hline
\end{tabular}

$r_{\mathrm{SO}_{2}}$, Cerebral oxygen saturation; $L \mathrm{~V}$, left ventricular; $Q p / Q s$, pulmonary/systemic blood flow ratio; $N A$, not applicable; $H b$, hemoglobin. $* P<.05$ compared with baseline (1-way analysis of variance). $\dagger P<.05$ compared with 30 minutes (1-way analysis of variance). $\ddagger P<.05$ compared with 120 minutes $(1$-way analysis of variance).

versely, $\mathrm{rSO}_{2}$ failed to predict cerebral $\mathrm{O}_{2}$ delivery (Figure 4) and $\mathrm{CBF}$ (Figure 5).

\section{Discussion}

The primary focus of this investigation was to establish the relationship between $\mathrm{rSO}_{2}$ and other physiologic indicators of cerebral oxygenation under conditions of hypoxemia and SVP. The main finding of this study is that in our acute model of SVP, $\mathrm{rSO}_{2}$ correlated well with $\mathrm{jvSO}_{2}$ and paralleled changes in arterial oxygenation. On the basis of our findings, a decrease in $\mathrm{rSO}_{2}$ can be expected when hypoxemia and SVP are introduced acutely. However, our study also shows that in this physiologic condition changes in $\mathrm{rSO}_{2}$ might have a limited value in reflecting changes in the adequacy of cerebral perfusion when simultaneous changes in arterial $\mathrm{O}_{2}$ saturation are occurring.

Detection and prevention of cerebral hypoxia might be critical to avoid adverse neurologic outcomes in children with congenital heart disease. ${ }^{8}$ Cyanotic children with SVP might be especially vulnerable to cerebral hypoxia and brain injury because they are hypoxemic and have a limited cardiac output reserve. ${ }^{16}$ NIRS technology has recently emerged as an effective and noninvasive tool to monitor brain oxygenation perioperatively. Clinically, NIRS-based brain monitoring with algorithms for interventions has been proposed as a tool to reduce the incidence of postoperative neurologic complications both in adult cardiac and congenital cardiac surgery.

Oxygen transport to the brain is a complex phenomenon influenced by several physiologic variables. These might have an effect on $\mathrm{rSO}_{2}$ and on its ability to detect cerebral hypoxia. ${ }^{17}$ Oxygen delivery to the brain is determined by $\mathrm{CBF}$ and $\mathrm{CaO}_{2}$, which in turn is influenced by hemoglobin concentration and arterial $\mathrm{O}_{2}$ saturation. NIRS has been shown to monitor oxygen saturation in a selected region of cerebral cortex. ${ }^{18}$ Previous work has demonstrated that $\mathrm{rSO}_{2}$ parallels closely cerebral venous saturation because of the overrepresentation of the venous capillary component

Table 2. Correlation of physiologic variables with cerebral $\mathbf{O}_{2}$ saturation

\begin{tabular}{llll}
\hline Variable & $\mathbf{R}$ & $\mathbf{R}^{2}$ & \\
\hline Arterial $\mathrm{O}_{2}$ saturation & 0.85 & 0.72 & $<.0001$ \\
Jugular venous $\mathrm{O}_{2}$ saturation & 0.83 & 0.71 & $<.0001$ \\
Arterial $\mathrm{O}_{2}$ content $\left(\mathrm{mL} \mathrm{O}_{2} / 100 \mathrm{~mL}\right)$ & 0.81 & 0.65 & $<.0001$ \\
Jugular venous $\mathrm{O}_{2}$ content & 0.74 & 0.56 & $<.0001$ \\
Cerebral $\mathrm{O}_{2}$ delivery & 0.29 & 0.08 & .1 \\
$\mathrm{~A}-\mathrm{V} \mathrm{O}_{2}$ saturation difference & 0.08 & 0.007 & .6 \\
Cerebral blood flow & -0.39 & 0.12 & .05 \\
\hline
\end{tabular}

$A-\mathrm{O}_{2}$, Arteriovenous $\mathrm{O}_{2}$ saturation difference. 


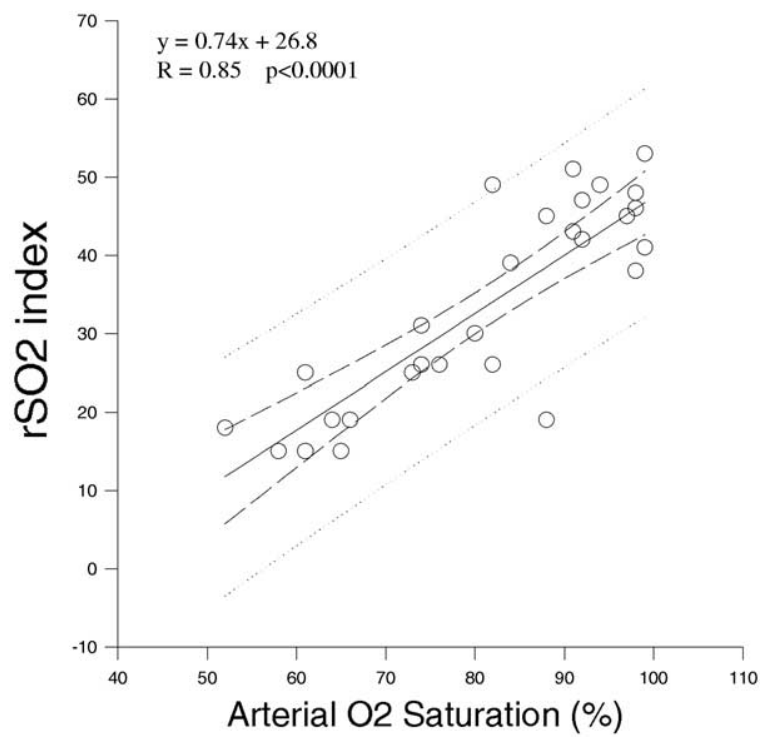

Figure 1. Correlation between cerebral $\mathrm{O}_{2}$ saturation $\left(\mathrm{rSO}_{2}\right)$ and arterial $\mathrm{O}_{2}$ saturation, with regression line and confidence-prediction intervals.

over the arterial component in the cerebral tissues. ${ }^{17,18}$ Kurth and colleagues, ${ }^{18}$ as well as others, ${ }^{12,17}$ found a significant correlation between cerebral saturation measured by using NIRS technology and cerebral venous saturation. In the setting of biventricular physiology and steady pul-

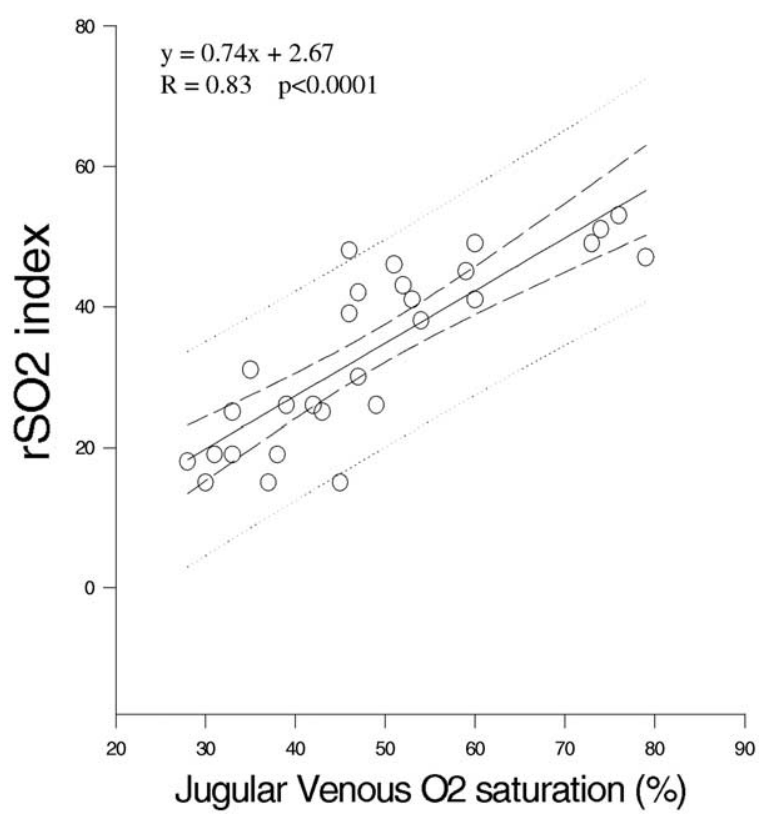

Figure 2. Correlation between cerebral $\mathrm{O}_{2}$ saturation $\left(\mathrm{rSO}_{2}\right)$ and jugular venous $\mathrm{O}_{2}$ saturation ( $\mathrm{juSO}_{2}$ ), with regression line and confidence-prediction intervals.

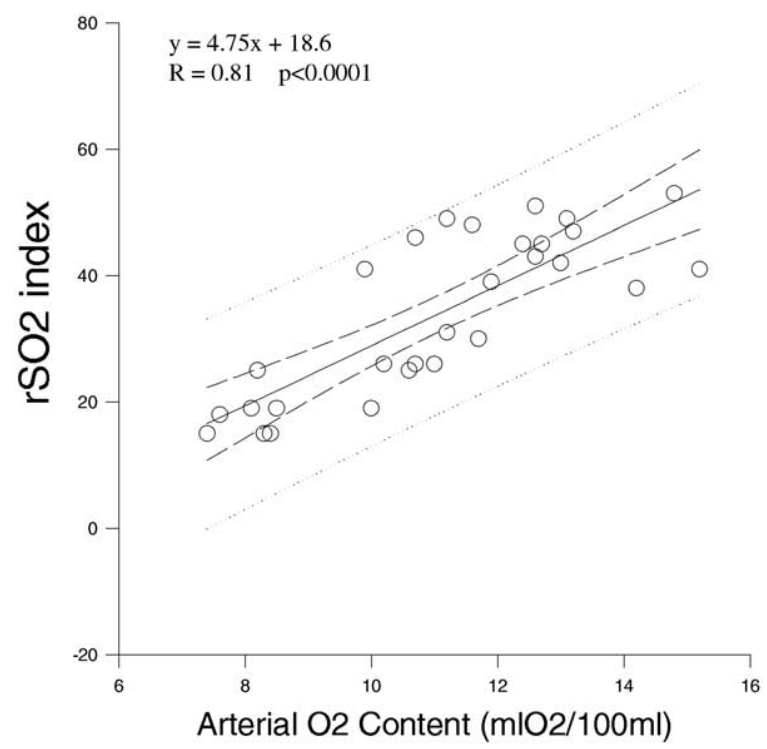

Figure 3. Correlation between cerebral $\mathrm{O}_{2}$ saturation $\left(\mathrm{rSO}_{2}\right)$ and arterial $\mathrm{O}_{2}$ content $\left(\mathrm{CaO}_{2}\right)$, with regression line and confidenceprediction intervals.

monary function, arterial $\mathrm{O}_{2}$ saturation and $\mathrm{CaO}_{2}$ are unlikely to change, at least over short periods of time. If cerebral metabolism and oxygen consumption remain constant during the same time interval, changes in cerebral venous $\mathrm{O}_{2}$ saturation and therefore $\mathrm{rSO}_{2}$ can be assumed to reflect changes in $\mathrm{CBF}$ and ultimately cerebral $\mathrm{O}_{2}$ delivery.

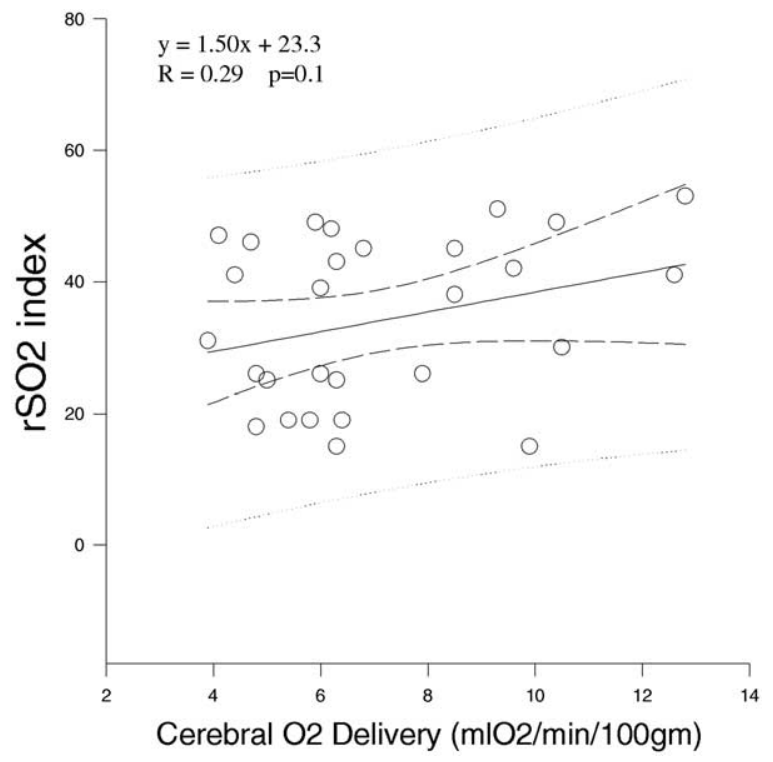

Figure 4. Correlation between cerebral $\mathrm{O}_{2}$ saturation $\left(\mathrm{rSO}_{2}\right)$ and cerebral $\mathrm{O}_{2}$ delivery, with regression line and confidence-prediction intervals. 


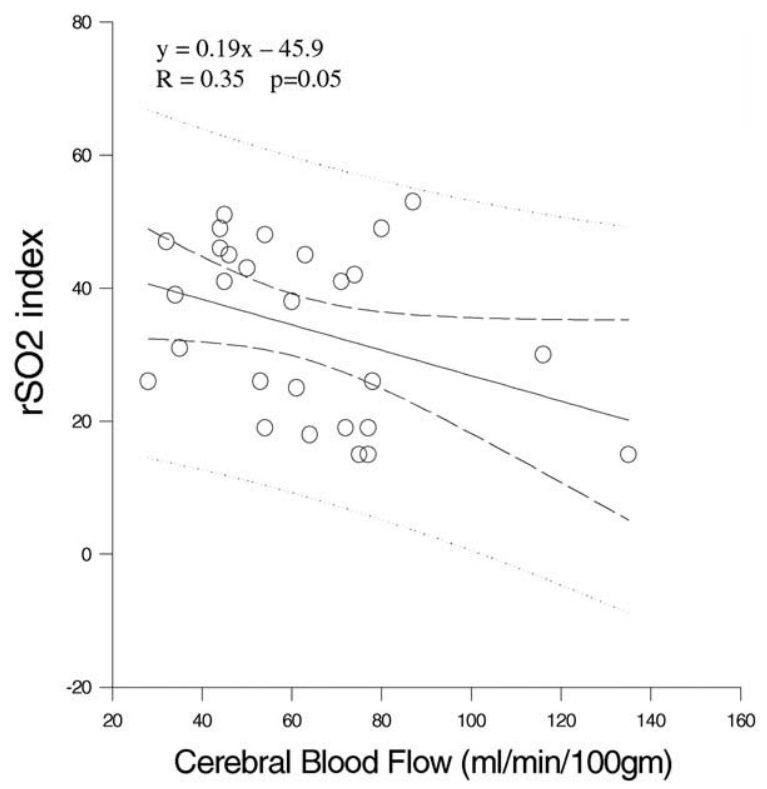

Figure 5. Correlation between cerebral $\mathrm{O}_{2}$ saturation $\left(\mathrm{rSO}_{2}\right)$ and cerebral blood flow, with regression line and confidence-prediction intervals.

On the basis of this, $\mathrm{rSO}_{2}$ monitoring has been found to be useful in clinical practice because it can provide information on the adequacy of cerebral perfusion. ${ }^{3-5}$

In SVP, however, changes in arterial $\mathrm{O}_{2}$ saturation can occur rapidly as a result of the varying balance between systemic and pulmonary vascular resistance. ${ }^{19}$ These could affect $\mathrm{rSO}_{2}$ and interfere with the ability of NIRS to reflect changes in the relationship between cerebral $\mathrm{O}_{2}$ supply and demand. As Table 1 shows, in our experimental model the $\mathrm{rSO}_{2}$ index decreased in parallel with cerebral $\mathrm{O}_{2}$ delivery and arterial $\mathrm{O}_{2}$ saturation as the SVP model was established. However, this correlation was lost when afterload augmentation was introduced because $\mathrm{rSO}_{2}$ increased significantly, whereas cerebral $\mathrm{O}_{2}$ delivery did not. In our experiment afterload augmentation caused a significant increase in arterial pressure and pulmonary blood flow through the aortopulmonary shunt, which in turn resulted in higher arterial $\mathrm{O}_{2}$ saturation and lower $\mathrm{PCO}_{2}$. These physiologic changes caused a modest decrease in $\mathrm{CBF}$. The net result of the higher $\mathrm{CaO}_{2}$ and lower $\mathrm{CBF}$ was that cerebral $\mathrm{O}_{2}$ delivery remained unaffected, whereas $\mathrm{rSO}_{2}$ increased significantly, tracking the increasing arterial $\mathrm{O}_{2}$ saturation.

Continuous monitoring of $\mathrm{rSO}_{2}$ allows rapid recognition of cerebral hypoxia ${ }^{20}$ and immediate feedback on the efficacy of therapeutic maneuvers aimed at improving cerebral oxygenation. ${ }^{3}$ The use of NIRS for brain monitoring has been especially studied in the setting of cardiac operations. In 250 children undergoing operations for congenital heart disease, Austin and coworkers ${ }^{8,9}$ found that using NIRS brain monitoring to guide interventions to improve cerebral oxygenation resulted in a decrease in the incidence of neurologic sequelae and shorter hospital stay. Similarly, NIRS has been proposed as a useful tool to monitor brain oxygenation both preoperatively ${ }^{10}$ and postoperativly, ${ }^{11}$ although the experience in these settings is more limited. The implications of our findings as they relate to $\mathrm{rSO}_{2}$ monitoring in children with SVP could be significant in that they unveil a physiologic situation in which the use of $\mathrm{rSO}_{2}$ as a surrogate indicator of the adequacy of cerebral perfusion might have limitations. The response to afterload augmentation noted in our piglets suggests that NIRS data need to be interpreted with caution if simultaneous changes in arterial $\mathrm{O}_{2}$ saturation are occurring. These should be taken into account when making assumptions on the efficacy of therapeutic maneuvers in improving brain oxygenation.

Our findings must be interpreted in light of the limitations inherent with the experimental model. Despite the fact that this model has been validated previously, it is unknown whether our experimental conditions reproduce cardiovascular changes occurring in children with SVP. Differences between animal species and human subjects could also influence $\mathrm{rSO}_{2}$ monitoring with NIRS. Additional limitations relate to the method used to increase afterload (ie, balloon inflation in the descending thoracic aorta). We used aortic occlusion because this method has been validated by others ${ }^{21}$ and is highly reproducible. In addition, because our piglets were already receiving inotropic support during the entire experiment, further increasing afterload through additional pharmacologic interventions would have been impractical. Nonetheless, we acknowledge that aortic occlusion might have produced physiologic changes in the SVP model that are not directly equivalent to those observed in clinical practice when afterload is manipulated pharmacologically. Also, the fact that afterload increases were produced 2 hours after creation of the model might have been associated with some deterioration of the experimental preparation.

In our study we did not measure intracranial pressure, and therefore we cannot draw conclusions on the effect of this variable on $\mathrm{rSO}_{2}$ changes. It is also possible that afterload augmentation induced changes in the cerebral circulation that affected the balance between arterial and venous components as detected by the NIRS signal, therefore influencing $\mathrm{rSO}_{2}$ values. Additional weaknesses relate to the lower hemoglobin concentration found in piglets, unlike the relative polycythemia seen clinically, and to the use of jugular venous saturation as opposed to sagittal sinus saturation to estimate cerebral venous oxygenation.

Despite the many limitations, this study could provide additional information on the use of NIRS in children with univentricular physiology. NIRS technology is useful be- 
cause it allows the rapid and noninvasive detection of cerebral hypoxia and the assessment of responses to therapeutic maneuvers aimed at improving cerebral oxygenation. Our study suggests that in the setting of $\mathrm{SVP}, \mathrm{rSO}_{2}$ trends need to be interpreted in the context of changes in arterial $\mathrm{O}_{2}$ saturation. Our findings do not diminish the value of transcranial NIRS in assessing cerebral oxygenation. However, they provide a useful adjunct to the interpretation of $\mathrm{rSO}_{2}$ changes when simultaneous changes in arterial oxygenation are occurring.

We thank Somanetics Corporation, Troy, Mich, for providing the NIRS equipment. We thank Dr Erle H. Austin for sharing with us useful information on the SVP model. We are grateful to Dr Kenneth G. Proctor for his invaluable support.

\section{References}

1. Wyatt JS, Cope M, Delpy DT, Richardson CE, Edwards AD, Wray S, et al. Quantitation of cerebral blood volume in human infants by near-infrared spectroscopy. J Appl Physiol. 1990;68:1086-91.

2. Kurth CD, Steven JM, Swedlow D. New frontiers in oximetry. Am J Anesthesiol. 1996;23:169-75.

3. Edmonds HL Jr, Ganzel BL, Austin EH 3rd. Cerebral oximetry for cardiac and vascular surgery. Semin Cardiothorac Vasc Anesth. 2004; 8:147-66.

4. Edmonds HL Jr. Multimodality neurophysiologic monitoring for cardiac surgery. Heart Surg Forum. 2002;5:225-8.

5. Daubeney PEF, Pilkington SN, Janke E, Charlton GA, Smith BC, Webber SA. Cerebral oxygenation measured by near-infrared spectroscopy: comparison with jugular bulb oxymetry. Ann Thorac Surg. 1996;61:930-4.

6. Prabhune A, Sehic A, Spence PA, Church T, Edmonds HL. Cerebral oximetry provides early warning of oxygen delivery failure during cardiopulmonary bypass. J Cardiothorac Vasc Anesth. 2002;16:204-6.

7. Fukada J, Morishita K, Kawaharada N, Yamauchi A, Hasegawa T, Satsu T, et al. Isolated cerebral perfusion for intraoperative cerebral malperfusion in type A aortic dissection. Ann Thorac Surg. 2003;75: 266-8.

8. Austin EH 3rd, Edmonds HL Jr, Auden SM, Seremet V, Niznik G, Sehic A, et al. Benefit of neurophysiologic monitoring for pediatric cardiac surgery. J Thorac Cardiovasc Surg. 1997;114:707-17.

9. Hofer AA, Haizinger B, Geiselseder G. Near-infrared spectroscopy during antegrade cerebral perfusion in neonates undergoing cardiosurgical repair [abstract]. Anesthesiology. 2002;96:A1284.

10. Kurth CD, Steven JL, Montenegro L, Watzman HM, Gaynor JW, Spray TL, et al. Cerebral oxygen saturation before congenital heart surgery. Ann Thorac Surg. 2001;72:187-92.

11. Hoffman GM, Stuth EA, Jaquiss RD, Vanderwal PL, Staudt SR, Troshynski TJ, et al. Changes in cerebral and somatic oxygenation during stage 1 palliation of hypoplastic left heart syndrome using continuous regional cerebral perfusion. $J$ Thorac Cardiovasc Surg. 2004;127:223-33.

12. Kusaka T, Isobe K, Nagano K, Okubo K, Yasuda S, Kondo M, et al. Quantification of cerebral oxygenation by full-spectrum near-infrared spectroscopy using a two-point method. Comp Biochem Physiol. 2002; 132:121-32.

13. Riordan CJ, Randsbaek F, Storey JH, Montgomery WD, Santamore WP, Austin EH. Effects of oxygen, positive end-expiratory pressure, and carbon dioxide on oxygen delivery in an animal model of the univentricular heart. J Thorac Cardiovasc Surg. 1996;112:644-54.

14. Mora GA, Pizarro C, Jacobs ML, Norwood WI. Experimental model of single ventricle. Influence of carbon dioxide on pulmonary vascular dynamics. Circulation. 1994;90(suppl II):II43-6.

15. Reinhardt CP, Dalhberg S, Tries MA, Marcel R, Leppo JA. Stable labeled microspheres to measure perfusion: validation of a neutron activation assay technique. Am J Physiol Heart Circ Physiol. 2001;280:H108-16.

16. Mahle WT, Tavani F, Zimmerman RA, Nicolson SC, Galli KK, Gaynor JW, et al. An MRI study of neurological injury before and after congenital heart surgery. Circulation. 2002;106(suppl I):I109-14.

17. Watzman HM, Kurth CD, Montenegro LM. Arterial and venous contributions to near-infrared cerebral oxymetry. Anesthesiology. 2000; 93:947-53.

18. Kurth CD, Levy WJ, McCann J. Near-infrared spectroscopy cerebral oxygen saturation thresholds for hypoxia-ischemia in piglets. J Cereb Blood Flow Metab. 2002;22:335-41.

19. Riordan CJ, Randsbaek F, Storey JH, Montgomery WD, Santamore WP, Austin EH 3rd. Inotropes in the hypoplastic left heart syndrome: effects in an animal model. Ann Thorac Surg. 1996;62:83-90.

20. Daubeney PEF, Smith DC, Pilkington SN, Lamb RK, Monro JL, Tsang VT, et al. Cerebral oxygenation during paediatric cardiac surgery: identification of vulnerable periods using near infrared spectroscopy. Eur J Cardiothorac Surg. 1998;13:370-7.

21. Buckberg GD, Fixler DE, Archie JP, Hoffman JIE. Experimental subendocardial ischemia in dogs with normal coronary arteries. Circ Res. 1972;30:67-81.

\section{Discussion}

Dr Donald B. Doty (Salt Lake City, Utah). It seems to be a little more directly associated but it is frontal blood supply. We would like to know motor blood supply rather than frontal lobe, so there are some limitations regarding the predictability of the technique you used. Plus, you have set up a very complex model in which you are trying to use the left ventricle as a single ventricle, totally disabling the right ventricle and then supporting these animals with multiple medications. Anybody who has ever done these kinds of experiments with single ventricles, either right-side ventricle or left-side ventricle, has found it extraordinarily difficult to sustain and support this acute experiment. We give you a lot of credit for being able to carry this through. Unfortunately, what we are left with is this question: Does this NIRS really offer any advantage over what we already have in terms of SVP where afterload and the medications and so on are so strongly influencing what we observe? I guess what the real question, after hearing all of this, is, how does it apply clinically? Have you tried it in patients after a Norwood procedure? Do you use it after palliation of a hypoplastic right ventricle?

Dr Ricci. Thank you for your comments. I share your view on the difficulty of the model. This model is not only difficult but also very humbling and we certainly lost a lot of animals in trying to refine it and get to this point.

Of course NIRS has been proposed and has been used with increasing frequency at many centers including ours, because it might provide some information on the balance between supply and demand and, therefore, on the adequacy of cerebral oxygenation. However, it has limitations. Our hypothesis was that, as NIRS is essentially a very reliable indicator of cerebral venous oxygenation, changes in arterial oxygenation could influence the NIRS signal and could affect the ability of this technology in providing information on cerebral oxygenation. Obviously after we got into our conclusions, our impression is that in SVP, since there is a possibility that the $\mathrm{CaO}_{2}$ might change in contrast to normal biventricular physiology, simultaneous changes in arterial saturation need to be taken into account when interpreting NIRS changes.

As far as the extent to which these findings would apply and change our management in clinical situations, I cannot answer that 
question. I can tell you that we are using this technology now in our pediatric intensive care unit for all our pediatric patients, including patients with SVP. We began using it relatively recently, so I do not have clinical data to share with you regarding this. However, knowing what we know now, let's say we see that the cerebral saturation by NIRS had declined by $20 \%$ in a child with SVP. Based on this and other clinical indicators, we would institute therapeutic maneuvers to try to correct that, with the assumption that cardiac output may be low. Then, we know that if we see a rise in cerebral oxygenation as shown by NIRS in response to the intervention, and that, for example, the NIRS increase corresponds to a simultaneous rise in arterial oxygenation, then that NIRS rise might not necessarily indicate better cardiac output in response to the intervention. It could simply reflect improved arterial oxygenation. I do not know whether the message is clear, but I think these findings insert an additional element in the equation when making clinical decisions based on NIRS, which I think is important.

Dr Doty. So the question is, does everybody who does this kind of work need to run out and buy one of these things tomorrow, or are you still content with getting along with what you had before, which is nothing?

Dr Ricci. I don't think I can answer that question based on these data.

Dr John Meyer (Boston, Mass). It seems to me that the longstanding problem with using this technology has been trying to figure out what is happening to the blood that is in the pathway of your NIRS signal versus what is happening in the parenchyma. What your information would indicate to me, or the way I would interpret it, is that the NIRS technology is picking up what is happening in the blood, not what is happening in the cerebral parenchyma. The problem of trying to separate out those two contributors to your NIRS data has been a difficult one. I think actually this is pretty good information to suggest that the NIRS signal may not be reflecting what is going on in the cerebral parenchyma, the neuronal cells, and is probably more reacting to or a function of what's happening in the blood that happens to be in the pathway between the signal. I think from that standpoint this is actually an extremely useful study and I congratulate you on doing it.

Dr Ricci. We used 0.25 .

Unidentified Speaker. A number of years ago, in the days when we were letting babies sit around waiting for a heart transplant, a colleague of mine in Salt Lake City looked at carotid blood flow but at lower oxygen saturation and it just drove home the physiologic point. He found that the flow, and actually what he calculated was a crude measure of oxygen delivery to the brain, was better at a lower $\mathrm{FIO}_{2}$ than it was higher. I guess it just drives home the point that oxygen delivery is ultimately determined by hemoglobin, oxygen saturation, and flow. Once again we learned the foundation of physiology here. Thank you.

Dr Ricci. Thank you. 